\title{
Christopher House
}

School of Architecture, Built and Natural Environments

University of Wales Trinity Saint David

Mount Pleasant, Swansea. SA1 6ED

Tel: 0044 (0)1792 483675, Fax: 0044 (0)1792 651760

e-mail: chris.house@uwtsd.ac.uk

\section{Jack Samways}

School of Architecture, Built and Natural Environments

University of Wales Trinity Saint David

Mount Pleasant, Swansea. SA1 6ED

Tel: 0044 (0)1792 481000, Fax: 0044 (0)1792 651760

e-mail: Jack.samways@uwtsd.ac.uk

\section{Allan Williams}

School of Architecture, Built and Natural Environments

University of Wales Trinity Saint David

Mount Pleasant, Swansea. SA1 6ED

Tel: 0044 (0)1792 483053, Fax: 0044 (0)1792 651760

e-mail: Allan.williams@uwtsd.ac.uk 


\section{Designing coastal management}

\section{strategies for populations with distinct}

\section{needs: The case of learning disabilities}

Keywords: Disability, coastal management, coastal access, photovoice.

\section{Abstract}

The Disability Discrimination Act (DDA 1995, amended 2005), Equality Act (2010), EU Disability Action Plan (2003-2010) and EU Disability Strategy (2010-2020) were designed to make equal opportunities a 'reality'. As $16 \%$ of the EU population is statutorily disabled, there are considerable implications for beach management. Common research examples given of beach users include swimmers, anglers and water-sport enthusiasts - but rarely people with learning disabilities (LD). This paper assessed the viewpoints of a group of beach users with LD and considered their appreciation of three different coastal classifications in South Wales, UK. Because of the nature of their disabilities, the research applied a participatory photo-interpretation methodology (photovoice) at these three beach locations. The research then compared the LD ranking of beach issues with rankings provided by members of the general public at the same beaches. The results demonstrated some similarities between LD and general public coastal needs, but identified the need for specific 
considerations to be made by beach managers for LD users. These included informed selfadvocacy, use and application of signage, instructive access and a requirement for baseline information gathering. The research proposes an Integrated Coastal Access Model (ICAM) from which Coastal Zone Management (CZM) and gatekeepers can consider the needs of people with LD within coastal strategies. Finally, this research also highlighted the use of photovoice in coastal research projects and the need for innovative methodological considerations when researching certain groups.

\section{Introduction}

Prioritising beach management for different interest groups is a CZM tenet (Phillips \& House, 2008). Groups with LD are ethically, numerically, legally and economically an important group who have had scant attention from coastal research and management. Although mainstreaming of policies directed at disability is now a social, legal and economic responsibility, coastal management research does not reflect this statutory agenda. A typical comment in the literature is as follows: 'Primary beach users include recreationalists/swimmers and water sport enthusiasts. There are a wide range of other miscellaneous groups, which include anglers, coastal climbers etc. In addition, research highlights that it is vital that the perceptions of beach user's be included at all levels of the planning process (Nelson et al., 2003). Despite the recognised need for inclusion, LD groups are rarely considered. Some progress has been made in analysing disability, such as the role of inclusion, accessibility, the reaction of diverse audiences (Tregaskis, 2004) and the accessibility of tourist attractions (Botterill \& Klemm, 2006). Nonetheless, past research has failed to focus on the unique needs of coastal locations and has often ignored the 'silent majority' of a population with LD. This paper addresses this omission, through the application of a photovoice methodology and the proposal of an access model. 


\section{Background}

Besides the implicit ethical reasons for considering LD groups, there is a strong legal and socio-economic argument for their importance in coastal management research. The UK's Disability Discrimination Act (DDA, 1995) and its partial replacement, the Equality Act (2010), outlined the requirement for all facility and service providers to engage with disabled access issues in site management and to provide equal rights of access (Goodall, 2006). Furthermore, since 2003 the EU disability strategy has made equal opportunities and mainstreaming disability in policy formulation an obligation (European Commission, 2007), and legislation to address discrimination against the disabled has been implemented in various parts of the world, e.g. the Americans with Disabilities Act (1990, USA) and the Disability Discrimination Act (1992, Australia). The EU Disability Action Plan (2003-2010) (European Commission, 2009), European Disability Strategy (2010-2020) (European Commission, 2010) and UN Convention on the Rights of Persons with Disabilities (UN, 2006) have set out the need for equal access and experience, which has implications for coastal locations. This progression towards legal responsibility and agenda-setting is occurring in many parts of the world (WHO, 2011) and coastal managers must therefore consider the implications and allow all users, regardless of their difficulties, to experience the same level of coastal involvement as the general population. Legislative support is a vital corollary for effective coastal policy implementation (McKenna \& Cooper, 2006), and hence LD statutory frameworks need effective policy action.

Nonetheless, one of the most vulnerable groups in society continues to be those with LD (Department of Health, 2001), as deliberate and non-deliberate exclusion persists in all aspects of their lives (Spink, 2005). Enforcement of the DDA (1995) means that intentional exclusion of persons with LD with regard to employment, education, buying or renting 
property is illegal. However, non-deliberate discrimination can cause many difficulties. The Disability Rights Commission (2004: 6-7) has stated that: 'considering the volume of people with learning or intellectual disabilities ... very little thought has been put towards making the environment user friendly for these people'. Of particular relevance to this research is the fact that the Marine and Coastal Access Act (2009) does not clearly highlight the specific needs of these beach users.

Furthermore, there are increasing socio-economic pressures that need consideration in coastal areas, and LD communities are integral to these developments. Expanding urbanisation, in addition to vast tourist numbers, has led to development and resource pressures that are challenges for future CZM (Leatherman, 2001; Small \& Nicholls, 2003). Disabled populations are not impervious to these social and economic forces, and their specific 'needs' require attention. Globally, ( 1 billion), $18.2 \%$ of the population are disabled and have disability based human rights (WHO, 2011). Within the EU population (499 million), 16\% (79 million) are registered disabled (European Commission, 2007), 12\% of whom are wheelchair users (5 million) (FPLD, 2003; Goodall, 2006; CSR Europe, 2007). In the USA the figures show 36 million with at least one disability (12\% of total population), 2.8 million of whom are wheelchair users (Disabled World, 2011; Newdisability, n.d.,). These statistics show a numerically significant population that must be accounted for in beach management. The question raised is what is the current state of beach access for these people and what research is being carried out to implement their views with respect to coastal issues into CZM? Furthermore, there is a consensus that the LD population is increasing, owing to improved diagnosis (Department of Health, 2001), and that therefore the needs of LD people will become of increasing importance to the Marine and Coastal Access Act in the UK and similar legislation in other parts of the world. Ensuring that the coast is accessible to all is 
part of the government's marine and coastal remit; clearly, that access must be available to everyone, regardless of relative needs. In addition, internet forums highlight the importance of coastal vacations because they allow LD individuals to experience exciting activities, friendship, independence, confidence and opportunities for self-reflection (e.g. Scope, 2015).

\section{Definition}

One difficulty for coastal managers is that there is no universally accepted definition or agreed term for LD. The literature and accepted terminology includes: intellectual disability, learning difficulties, special educational needs, additional needs, complex needs, mentally handicapped, learning differences and special needs, and qualifying terms such as mild, severe and profound (FPLD, 2014). This research used the term LD because, in a survey of these groups, 36\% preferred the use of this term (NetBuddy, 2012); in addition, it is widely applied within official literature. However, LD is difficult to define because the individuals include those with Down's syndrome, Nett syndrome, Fragile X syndrome and some autistic spectrum disorders. Their needs are often complex and may include physical and sensory impairments and/or challenging behaviour (FPLD, 2014); associated definitions are therefore implicitly contentious. LD are defined by the Department of Health (2001: 56) as 'long lasting effects on a person's development that will have implications on personal ability to function independently and to understand new and complex information'. Recent definitions have used 'persons with physical or mental impairment. The impairment has substantial and long-term adverse effect on their ability to perform normal day-to-day activities' (Equality Act, 2010: 4). Potential difficulties experienced by people with LD in coastal areas include those associated with independent action, new information, signage, physical access, safety, beach infrastructure and enjoyment, all of which are often exacerbated in the coastal zone. Nonetheless, difficulties of definition are marginal compared with the need to remove labels 
and prejudices. Hence, coastal managers need to be aware of definitional complexity but also to identify specific and non-specific needs.

\section{Methodology}

Obtaining comments from LD groups on perception and access tends to be logistically hard, time-consuming and costly (Hanley, 2005), and there is need for innovative methodological tools that can facilitate effective information gathering. Photoparticipation methods, such as photovoice, provide such a tool. By asking participants to express their point of view or represent their community through photographing themes that highlight the research themes, photovoice allows researchers to record and reflect on communities' views and to develop dialogue, context and knowledge that can be communicated to policy makers. It also allows researchers to avoid the methodological problems associated with predetermined paradigms and establishes communities' ownership of their views (Wang \& Burris, 1997). The method has been increasingly used in community-based public-health research (e.g. Haines-Saah et al., 2013), in tourism studies and stakeholder participation projects (e.g. Balomenou \& Garrod, 2014), in environmental research (e.g. Lawler \& Patel, 2012) and in disability research (e.g. Woodgate et al., 2012). However, although Clarke et al. (2013) highlighted the potential of this approach for coastal research it has not been applied in the coastal zone and certainly not in the LD framework.

The approach used in this study involves a triangulation of research (Balomenou \& Garrod, 2014) that cross-references the data from different points: pre-fieldwork talking mats, photo fieldwork and follow-up interviews. Furthermore, it triangulates between data from the LD group, from the general population and from informal interviews with various gatekeepers. 
'Gatekeeper' is a widely used term that for this research refers to groups or individuals who enable people with learning disabilities to access coastal locations.

This study applied an observational investigatory style, integrating ethnographic and grounded theory techniques using a photovoice methodology. The approach allowed researchers to gain a more meticulous insight into behaviour and hence permitted a detailed consideration of coastal management agendas. Furthermore, it developed an appropriate level of contact with potential participants and encapsulated a reflexive technique to photo-analysis (Stewart et al., 2004; Hurworth et al., 2005). A focus group that fitted the detailed criteria (including required guardian consent, risk assessments and institutional regulations) was formed, consisting of five participants aged between 30 and 51: David, Claire, Pauline, James and Matt. Their support worker/gatekeeper (Ben) took part in data gathering by independently taking photographs of features that he perceived would emphasise the ability of people with LD to enjoy and gain access to the coast. Ben's independence from the cohort allowed valuable expert comment and for cohort results to be autonomous of the gatekeeper's influence, which is an important consideration within this kind of research (Clegg, 2004; Dye et al., 2004; Lewis and Porter, 2004; Knight et al., 2006).

Four initial whole-day contact sessions were undertaken, grounded in the work of Knight et al. (2006) on ethics and informed consent, and using factsheets based on Mencap (2002) guidelines:

- Using plain English

- Using layout and design

- Using symbols, drawings and photos

- Using technology to make ourselves clear. 
Additional meetings focused on participants' inherent knowledge of coastal zones and their allocated beaches, developing talking mats to assess participants' pre-visit understanding of coastal locations (Germain, 2004). Talking mats are an acknowledged tool that uses unique, specially designed picture-communication symbols that are attractive to all ages and communication abilities. This mosaic approach was undertaken every Friday for five weeks, followed by a pilot field visit.

Beaches chosen covered three of the five beach classifications suggested by Williams and Micallef (2009), and were Swansea Bay (urban), Caswell Bay (village) and Rhossili Bay (remote beach) (the other classifications are resort and rural). The classification system epitomised the distinct and common beach environments found in many countries; the three selected are typical of the region and demonstrate the spectrum of the classification system.

The methodology involved giving each participant two 27-exposure disposable cameras at each location. They were asked to 'take a walk around the beach in any direction', which gave them ownership of their walk. On their route they photographed features that they liked (camera 1) and did not like (camera 2). Investigators aids recorded each participant's behaviour by using supplied forms to create a comparable annotation framework for group dynamics. Freedom of choice is an important methodological consideration in such studies: participants could take photographs in their own time and of any aspect important to them (Yamashita, 2002; Booth \& Booth, 2003; Dakin, 2003; Germain, 2004; Stewart et. al., 2004). By asking participants to take photographs of both liked and did not like features, this research attempted to ensure that participants knew that expressing each opinion was equally acceptable and important. Finally, both participants and investigators had duplicate copies of all photographs to warrant ownership (Booth and Booth, 2003; Stewart et al., 2004). 
However, 'photographs alone, considered outside the context of their own voices and stories, would contradict the essence of photovoice' (Wang, 2005: 7). Hence, to comply with the photovoice approach, the research applied extensive informal, semi-structured, one-to-one interviews. Each participant chose the photographs to discuss. Owing to the nature of their disabilities, the photo interpretation phase (as well as the data collection phase) was timeconsuming, usually involving a series of interviews/sessions totalling approximately four hours per participant, per location. All photos were coded depending on the name of participant, the category under which they had been taken, and the location. Coding of each photo corresponded with notes taken by researchers and recorded with a digital recorder during interviews. Interviews focused on the reasons for, and thoughts and feelings about each image to help reveal the decision-making process, common themes and the implications for coastal management. In an attempt to remove instances of bias and subjectivity, considerable care was taken in using non-suggestive language, questions or body language. Participants had as much time as possible to discuss all of their photographs, so participant interviews took several sessions and weeks. Figure 1 and Table 1 provide an extract of inherent data contained within one photo and subsequent interviews. While these approaches are time-consuming, they provide an opportunity to develop a thorough understanding from the perspective of the group being studied and hence their priorities and preferences (Wang, 2005).

Results and subsequent analysis of issues delineated by the LD group enabled comparison with a cohort from the general public (GP) on the research beaches. A total of 108 people were surveyed based on a systematic sample of age and gender at the three beaches. The 
Learning disabilities and coastal access Figure 1 An illustrative photo dissection based on photovoice methodology image (24 James/Caswell/Do not Like)

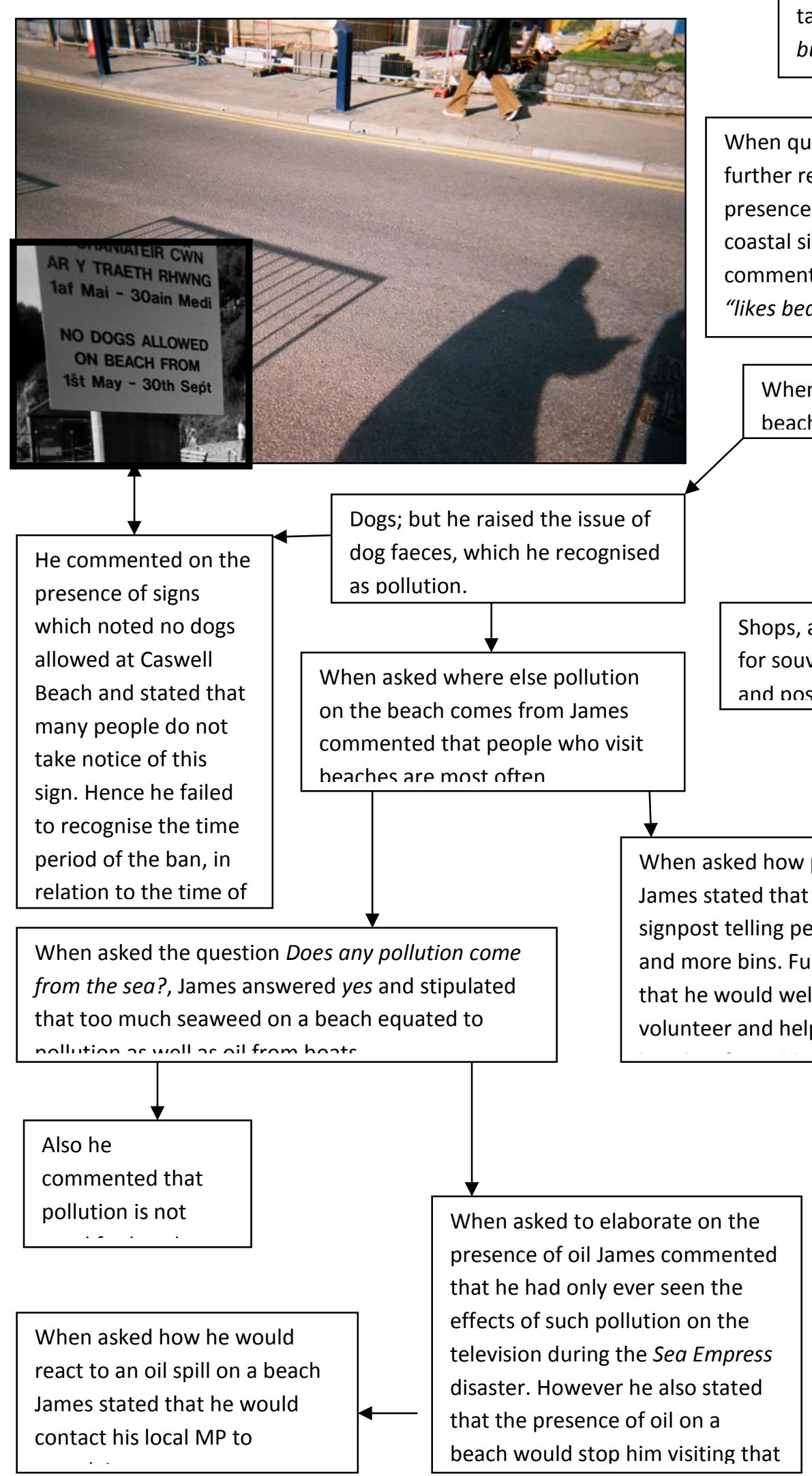

This photograph was taken at Caswell Bay by James; when asked he revealed that his intention was to take a photograph of the "cowboy builders" working on the public

When questioned further regarding the presence of facilities at coastal sites James commented that he "likes beaches with
Based on the presence of a portable toilet James began a five minute monologue regarding the toilet's similarities to $\mathrm{Dr}$.

\section{$\downarrow$}

When asked what else he liked to see at the beach he responded with:

Shops, as they were good or souvenirs, ornaments and postcards.

Car parks were a
very important
feature in beach
sites, as they
allowed more
people to visit
take notice of this sign. Hence he failed to recognise the tim period of the ban, in

When asked the question Does any pollution come from the sea?, James answered yes and stipulated that too much seaweed on a beach equated to nollution a woll or oil from honte

Also he commented that pollution is not

When asked how he would react to an oil spill on a beach James stated that he would beach would stop him visiting that
When asked how he would reach a coastal site James said that he would go in a minibus or car and would be taken by his care worker or family members. He says that he wouldn't go on his own as this would be too dangerous. James highlighted the tide and strangers as dangers on the beach but he failed to recognise the risks from pollution, which was one of his previously mentioned points of 


\section{Interpretation}

Thus from image (24 James/Caswell/Do not like) the following points of interest (key features) were highlighted for analysis:

- The presence of facilities at coastal sites was important for James.

- The provision of designated car parks at a beach site allows visits by groups or individuals such as James, who would be unable or unwilling to travel alone; it provides the ability to reach a site of interest with the aid of care workers or gatekeepers.

- During this conversation James failed to recognise many of the inherent dangers present in a semiuncontrolled landscape such as Caswell Bay.

- While James highlights signposts as an important feature at a coastal site, instructing people on how to treat such environments, he himself fails to correctly interpret the signage.

- Pollution is a subject of interest for James; he would be open to the opportunity to help conserve a landscape and environment such as this if he was given the chance. However, he confuses natural environmental features such as seaweed with pollution.

Table 1 An exemplar of image interpretation (figure 1) 
survey ranked beach priorities identified by the photovoice research and asked the public to allocate a Likert (1-7) assessment of their beach priorities.

\section{Results and Discussion}

This section is structured on the categorisations set out in Table 2. The findings from the gatekeeper results are analysed first, followed by those from the LD group. Thereafter, comparisons with the GP cohort and the findings' contribution to coastal management are considered. Finally, the research presents an Integrated Coastal Access Model (ICAM) to create a framework for the inclusion of the LD population in coastal management.

\section{Support worker insight (Ben)}

Following an interpretive approach to ethical research and in an attempt to mitigate intervention, the support worker photographed aspects of the locations that he thought would affect or limit participants' enjoyment of coastal locations. In total, he raised 16 access issues, 12 of which were categorised under the 'interactive landscape features' subsection. In particular, he felt that the presence of dogs on a beach was a 'potentially terrifying' experience to certain individuals with LD. More generally, Ben expressed a concern for lack of physical access, as many people with LD have a spectrum of disorders, which may include sight (including spatial awareness and depth perception), hearing and mobility problems (Disability Rights Commission, 2004). For example, he commented on the absence of visible pedestrian crossings between car park and beach, noting that someone with a learning disability could find this both 'impassable' and 'intimidating'. Furthermore, he suggested that the presence and form of danger or warning signs is an important access factor: for example, lack of symbolic representation can make signs meaningless to an individual with literacyrelated challenges. Coastal research on the experience of the general public supports this view, with an 'increased perceived effectiveness of warning signs, when combinations of 
Table 2 Summary of results from LD cohort, gatekeeper (GK) and GP cohort

\begin{tabular}{|c|c|c|c|c|c|c|c|c|c|}
\hline \multirow{2}{*}{$\begin{array}{c}\text { Learning Difficulties } \\
\text { (LD) cohort: access } \\
\text { issues }\end{array}$} & \multicolumn{5}{|c|}{ LD Individuals } & \multirow{2}{*}{\begin{tabular}{|l} 
Sub \\
total \\
rank
\end{tabular}} & \multirow[b]{2}{*}{$\begin{array}{l}\text { GK } \\
\text { Ben }\end{array}$} & \multirow{2}{*}{$\begin{array}{c}\text { GP } \\
\text { Mean } \\
\text { Likert } \\
(7) \\
\end{array}$} & \multirow{2}{*}{$\begin{array}{c}\text { GP } \\
\text { Rank }\end{array}$} \\
\hline & \multicolumn{5}{|c|}{ (names changed for confidentiality) } & & & & \\
\hline \multicolumn{8}{|c|}{ Visual Landscape Features } & & \\
\hline Scenery/aesthetics & 8 & 7 & 17 & 4 & 1 & 37 & & 6.58 & 2 \\
\hline Buildings & 2 & 4 & 6 & 2 & 1 & 15 & & 3.33 & 22 \\
\hline Weather & 1 & 2 & 3 & 1 & 3 & 10 & & 4.33 & 17 \\
\hline \multicolumn{8}{|c|}{ Interactive Landscape Features } & & \\
\hline Visitor facilities & 2 & 4 & 3 & 7 & 3 & 19 & 1 & 5.39 & 7 \\
\hline Flora & & 5 & 6 & 3 & 2 & 16 & & 5.15 & 11 \\
\hline Fauna & 1 & 3 & 5 & 4 & 1 & 14 & & 5.20 & 10 \\
\hline Litter/pollution & 5 & 2 & 3 & 4 & & 14 & 1 & 6.84 & 1 \\
\hline Footprints & 3 & 3 & 2 & 4 & 1 & 13 & & 3.48 & 21 \\
\hline Physical access & 5 & 1 & 4 & & 1 & 11 & 4 & 5.60 & 5 \\
\hline Signage & 4 & & 1 & 1 & 2 & 8 & 5 & 4.36 & 16 \\
\hline Sand patterns & 3 & 1 & 1 & & 2 & 7 & & 2.71 & 25 \\
\hline Water & 1 & 2 & 3 & 1 & & 7 & & 6.02 & 4 \\
\hline Coastal walk & 1 & & 3 & 1 & 1 & 6 & & 5.38 & 8 \\
\hline Dogs/horses & & 1 & 1 & 4 & & 6 & 1 & 4.40 & 15 \\
\hline Tide & 2 & & 1 & 1 & & 4 & & 4.57 & 13 \\
\hline \multicolumn{8}{|c|}{ Social and Sensory Landscape Features } & & \\
\hline Recreational activities & 2 & 8 & 6 & 12 & 2 & 30 & & 3.30 & 23 \\
\hline Friends/family/carers & 1 & 3 & 2 & 3 & 1 & 10 & & 4.55 & 14 \\
\hline Transport & 2 & 1 & 1 & 3 & 1 & 8 & & 3.68 & 19 \\
\hline Observation of Activities & & 1 & & 4 & & 5 & & 2.55 & 26 \\
\hline Socialising & & & 3 & 1 & 1 & 5 & & 3.54 & 20 \\
\hline Feelings & & 4 & & & & 4 & & 5.36 & 9 \\
\hline Self & & 1 & 1 & 1 & 1 & 4 & & 4.13 & 18 \\
\hline Time of Visit & & 2 & 2 & & & 4 & & 2.77 & 24 \\
\hline \multicolumn{8}{|c|}{ Subjective Perceptions } & & \\
\hline Safety & 2 & 1 & 1 & 1 & 1 & 6 & 2 & 5.56 & 6 \\
\hline Right to access & & & 1 & 2 & 2 & 5 & & 6.44 & 3 \\
\hline Dangers & & & 1 & 1 & & 2 & 2 & 4.93 & 12 \\
\hline Issues total & 45 & 56 & 77 & 65 & 27 & 270 & 16 & & \\
\hline $\begin{array}{l}\text { Number of photos } \\
\text { analysed }\end{array}$ & 10 & 18 & 26 & 20 & 10 & 84 & 11 & & \\
\hline
\end{tabular}

NB Owing to the reflexive technique employed, the issues total and number of photographs analysed do not correlate. Furthermore, Table 1 does not attempt to highlight the value of an 'access issue' by how many photographs are related to each subject because in reality it is plausible to infer that those topics which fail to raise much interest, such as 'danger' and 'safety', are just as important as, if not more than, those which raised considerable reactions from participants. 
words and symbols are used' (Williams \& Williams, 1988: 337). However, Ben's contribution did highlight a blunt contrast with the established coastal signage literature. Warning signs positioned at the beach entrance present quite a stark and intimidating message that would deter LD groups from accessing the beach (Figure 2). This is in complete contrast to the views of the general public, where beach access point signs to warn about potential dangers were considered positive for accessibility by $88 \%$ of beach users (Williams \& Williams, 1988, 1991). The general population assimilate and internally measure relative risk so, although physical and symbolic features are important, they are not generally a barrier to access. Ben's concerns therefore drew attention to some acute and intricate coastal access considerations for LD groups. For LD access to be encouraged, physical access features need to be present and careful consideration needs to be put into the design of symbolic features.

\section{LD cohort findings}

\section{Visual landscape features}

Access issues deemed distant or non-interactive in both a physical and a social context were designated as 'visual landscape features' (Table 2). These issues were collectively commented on 62 times (23\% of the total number of comments) by participants, and perceptions were generally mixed. The majority of responses remarked that cliffs, open vistas and surrounding vegetation created an impressive and interesting backdrop. However, buildings within the landscape evoked varied responses. In most cases, structures such as storm overflows and houses on cliff tops were regarded as 'ugly' and were considered to detract from the natural appeal of a local environment. James and Matt commented that, given a choice, they would prefer to visit more scenic and less urbanised coastal landscapes. The remaining members of the group stated that buildings in the landscape would not deter 
Figure 2 A selection of LD participants' images based on the photovoice methodology
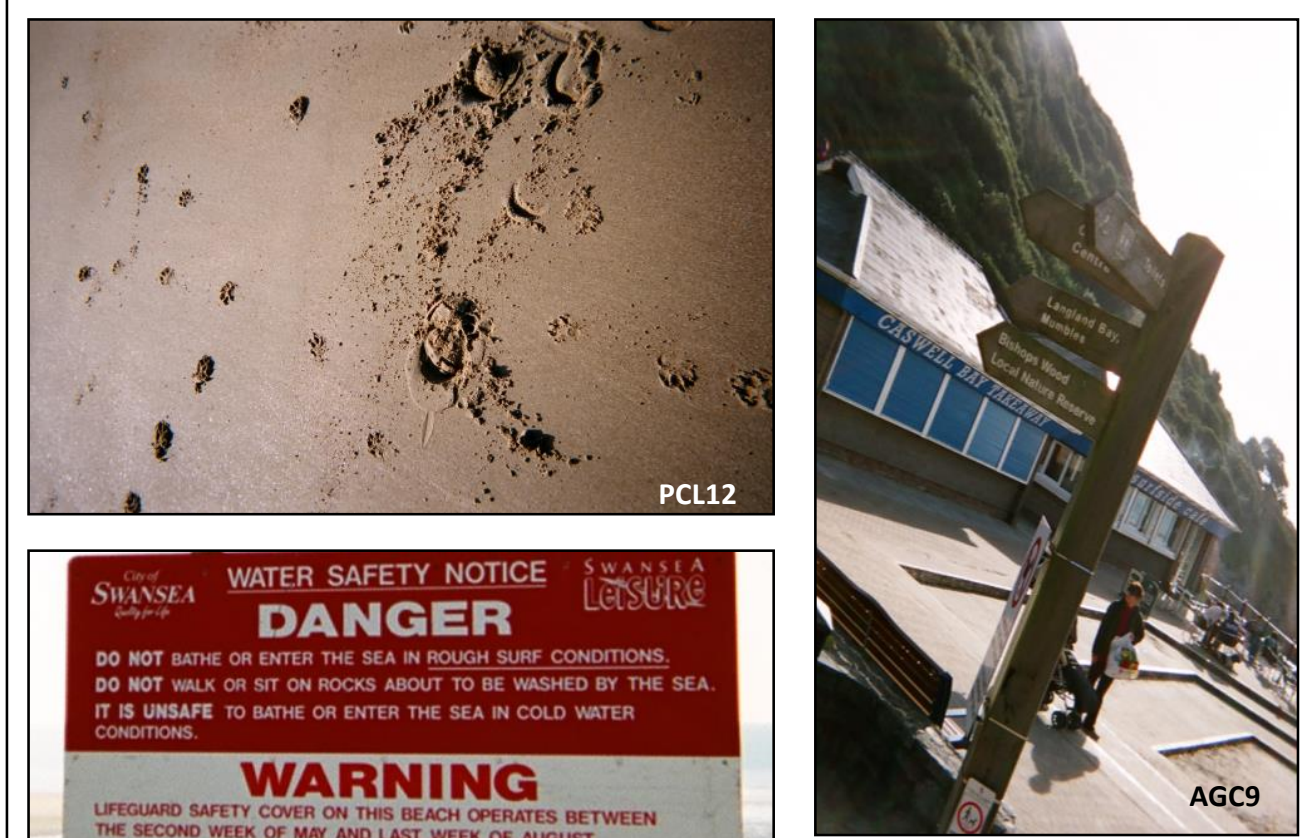

THE SECOND SAFETY COVER ON THIS BEACH OPERATES BETWEEN

RED DANCEP WER OF MAT AND LAST WEEK OF AUGUST

REFEGUARD SEPMICE IS FOT IN ARE NOT DISPLAYED WHEN THE

ANYONE DISAECARDING THIS ADVICE MAY.

ANYONE DISREGARDING THIS ADVICE MAY PLACE THEIR LIFE AT RISK.

Lefor
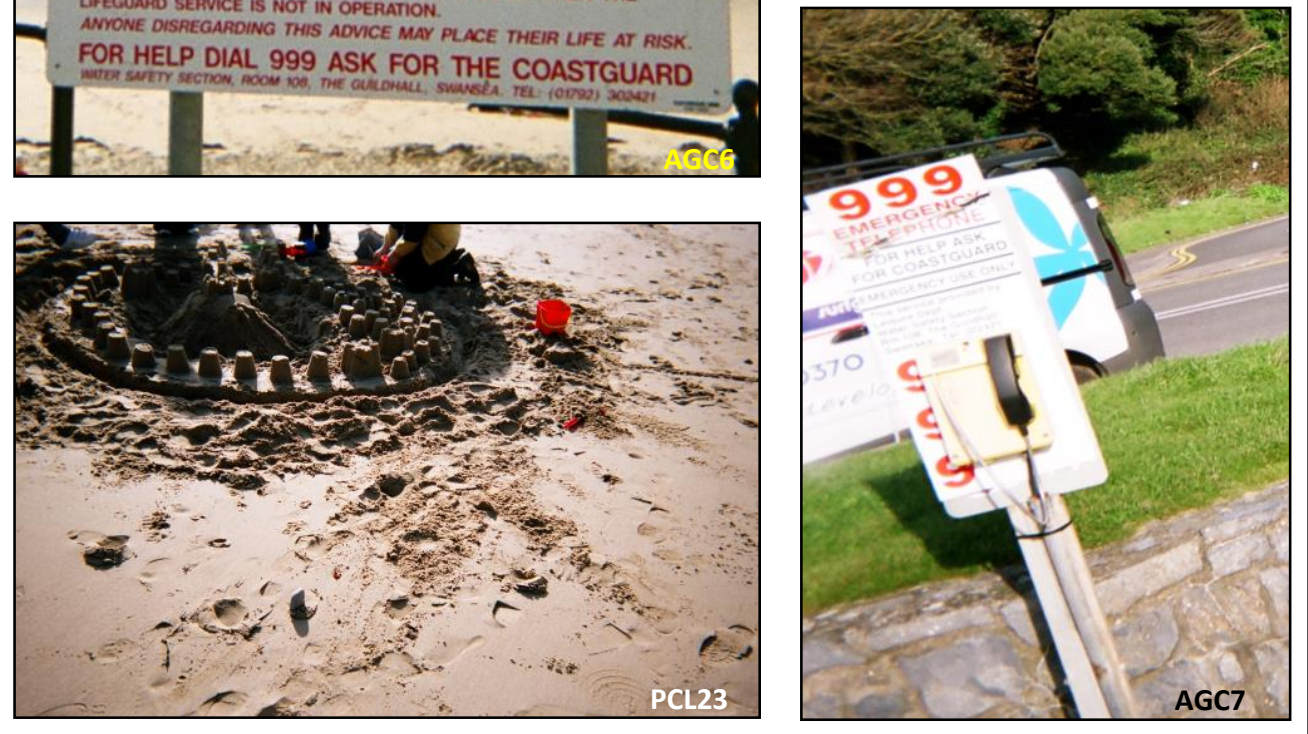
them from visiting sites (Table 2) on the proviso that they were low profile and architecturally blended with the landscape. This emphasis on natural scenery and considered architecture concurs with the general population's views on coastal locations (Ergin et al., 2006, 2008; Rangel-Buitrago et al., 2013).

The findings identified differences of opinion in relation to climatic conditions. While Claire and David commented that poor weather conditions would discourage them from visiting a coastal site, supporting Williams and Lavalle's (1990) statement that landforms are often influenced or even dominated by weather conditions, other participants stated that they would visit the coast despite unfavourable climatic conditions because it was an opportunity of 'getting out'. These viewpoints might suggest that such sections of society have similar interests and ideas regarding coastal aesthetics to those of the rest of the population. However, such similarities should not create complacency among coastal managers, as elemental differences still exist between these groups and the rest of the population. For example, from designated visual aesthetics and scenery images, only 5\% of the responses referred directly to the presence of the sea as a landscape feature. This lack of interest in what some people might consider the most striking feature of a coastal landscape directly contradicts Yamashita's (2002: 3) statement that: 'Water is one of the most important aesthetic elements of the landscape'. Furthermore, while four participants appeared to understand differences between fabricated and naturally formed landscape features, Matt did not, commenting that cliffs were created 'by humans some 3000 years ago'.

\section{Interactive landscape features}

The category of 'interactive landscape features' reflected the ability of participants to interact with and enjoy the landscape. In total 12 issues were identified and 125 subjects (constituting $46.3 \%$ of the total) discussed during photo-interpretation sessions (Table 2). 
Many participants found it difficult to interpret the exact meaning of signage. With the exception of Matt, who correctly identified that winter water sports might be dangerous, the participants who attempted to interpret beach safety guidelines were often at a loss regarding the exact meaning of the presented information. Furthermore, semantic differential tests proved that signs need a combination of words and symbols to improve effectiveness (Williams \& Williams, 1988). Nonetheless, even though the LD group misinterpreted signs, their adherence to their perceived meaning was $100 \%$ and this suggests that carefully considered signage would have a high adherence rate.

Contrary to the support worker's expectations, no participant raised any problems with the presence of domesticated animals such as dogs and horses. This is different from the findings of Williams and Tudor (2009), who showed that, at 25 beaches in Wales, $82 \%$ of the general public on resort/urban beaches wanted dogs banned, as opposed to 53\% of beach users on rural beaches. Nevertheless, the presence of such animals in the coastal environment did create other access issues. For example, James misinterpreted a 'no dogs allowed' signpost because he was not able to understand the notice's seasonality: i.e. that dogs were allowed on the beach only in the winter period (Figure 1). This led him to suggest that signposts of this nature 'should be ignored' because he observed other beach users were ignoring the signs and 'breaking the law'. This demonstrates the importance of carefully considered signage that is less prone to misinterpretation, e.g. following the format of the Picture Exchange Communication System (PECS, 2014).

Furthermore, visitor facilities were identified as a source of souvenirs, refreshments and somewhere warm to sit and hence, shops and cafés were seen as important attractions. 
However, the presence of such attractions was not a dominant factor in preferred beach selection. Facilities such as WCs and car parks were more important because they allowed 'longer' visits. This viewpoint corroborates the findings obtained for general beach user preferences (Williams and Tudor, 2009).

As mentioned earlier, participants became confused between what constituted natural and manmade coastal features. When questioned regarding the presence of seaweed, James commented that in certain circumstances this material should also be categorised as litter. Interestingly, the other LD participants shared this viewpoint and they assumed that the seaweed litter presence was due to beach visitors. When asked where litter/pollution originated, they recognised that many artefacts would have come both from beach users and/or from boats at sea. David, discussing pollution at Caswell Bay, identified an orange substance seen leaking out of a storm overflow pipe as toxic waste. The majority of David's subsequent photo-analysis focused around this pipe, with the comment 'imagine if your kids fell in that'. When asked how this problem should be ameliorated, David stated that he would have the pipe diverted or the area cordoned off to prevent human or wildlife interaction. When informed that the orange substance was actually iron ochre, he still insisted that signs 'should be put up', so that people like him could be aware of its whereabouts, purpose and any possible danger.

The presence of sand patterns and footprints were identified by all participants, although in some circumstances the two processes were confused (Figure 2). Incidences of footprints, whether human, bird, dog or horse, allowed participants an opportunity to debate beach rights of access. Occurrence of sand patterns and subsequent discussion enabled researchers to gauge a participant's inherent knowledge of natural beach functions. By asking a series of 
questions relating to how such patterns were formed (e.g. ripples), where they were found and whether participants liked or disliked them, it was possible to extrapolate that, while most liked such features, one member was able to identify that ripples were a product of natural processes and two commented that they were 'manmade'.

No participants commented specifically on the presence of coastal paths at any of the locations. Nevertheless, in following photo-interpretation, usually when analysing images of cliffs and surrounding vegetation, four participants recognised the existence of handrails/fences. Questions based on whether they enjoyed using coastal paths had mixed responses: three commented that they would consider using paths to gain access to other coastal sites, on condition that regular rest points were available. Pauline and Claire, who both mentioned mobility problems, stated that, given the choice and without regular support from a handrail, they would be reluctant to use this resource. Claire highlighted her preference for staying near main beach access points, as this was where she felt most comfortable.

Identification of flora and fauna appeared to be highly dependent on the participant's interest in such landscape features. Pauline directly expressed her enjoyment and interest in visiting coastal sites in pursuit of watching wildlife, and James noted an interest in what lives in rock pools. With respect to coastal management $(\mathrm{CM})$ implementation of these findings, there would need to be a ready supply of wildlife information in the form of pamphlets, notice boards, Smart media apps, etc. which were appropriate for different groups and which would usually be communicated to LD people via a gatekeeper. With regard to handrails, these are usually located at points of danger for the general public, whereas LD people would like them 
more frequently because they can be a prerequisite to access. Coastal walks often include rest points, but all the above need incorporation into any coastal plan.

\section{Social and sensory landscape features}

The category 'social and sensory landscape features' was given to those access issues that reflected the LD group's feelings regarding beach visits, in addition to how they related themselves to other beach users. The term refers to participants' interaction with other beach users, friends and family during site visits, as well as auxiliary issues such as transport and recreation. The importance of conducting analysis and research into social beach use is further highlighted by Tregaskis (2004), who comments on the nature of disabled access to the countryside and states that people with physical or programme access requirements often visit areas of interest with their friends and family. This outcome supports the idea that $\mathrm{CM}$ decisions should be inclusive in order to serve both the public and those with LD.

In all, 70 subjects were raised in this category and discussed by participants ( $26 \%$ of the total) (Table 2). Photos that focused on enjoyment of social interaction at beaches were important. Pauline discussed how coastal visits are an essential feature in her life, as beaches provide a large open space for socialising, meeting people and communicating. James discussed how the coastal environment was just one of many outdoor places he 'loves' going to with friends or family. However, while other group members concurred that visiting beach landscapes with others is an enjoyable experience, only Matt expressed a willingness to visit such areas alone using public transport. Other participants, whether because of transportation problems or safety concerns, stated reluctance in taking trips alone to coastal attractions.

Additionally, 30 of the 70 subjects discussed related to the participants' enjoyment of beach recreational activities. Characteristically, actions such as making sand castles, playing 
football/cricket, fishing, flying a kite, paddling, swimming, rock climbing, walking and surfing were all identified as activities that participants had either tried or would like to try. However, after several in-depth discussions with focus group members it became clear that, while a significant amount of pleasure was gained from partaking in recreational activities, an equal amount of satisfaction could be achieved through simply watching other beach users partake in social recreation. Furthermore, the research highlights a willingness of the participants to get involved in social interaction through personal volunteering. For $\mathrm{CM}$ implementation, the findings suggest that transport coordination, socialisation activities (actual doing/watching) and volunteering are important considerations.

\section{Subjective perceptions}

Tregaskis (2004) suggests that people with disabilities have a heightened sense of risk and self-awareness pertaining to their own ability to enjoy facilities and resources. Within the present research, this point has been termed 'subjective perception' and is a sensitivity to danger, safety and access. While pollution, tidal movements and misinterpretation of signs raise safety concerns, these issues were generally not included in participants' thoughts and feelings pertaining to their own protection. Hence this section only accounts for $13(5 \%)$ of the 270 issues raised during interviews.

Results showed that David correctly identified dangers associated with pollution for both wildlife and other beach users, but, unlike James, he stipulated that pollution would not deter him from continuing to use beaches for recreation. However, when asked to describe other potential dangers in coastal environments, David was the only participant to recognise associated dangers with the surrounding cliffs, stating that fences and barriers prevent people falling from coastal paths. While all five participants knew that tides were a dangerous phenomenon to be treated with caution and respect, none were able to identify what the 
correct procedure would be in an emergency. When they were questioned further, it became apparent that no group members could describe a tidal cycle or where to find information that would enable them to make an informed decision about which tidal state would be preferable for a visit to a beach. Hence, coastal managers need to consider the level of understanding and information required to achieve preferable user safety behaviour.

In relation to signage, this group partially conforms to the findings of other beach users, but there are some differences in how the understanding of signage can lead to different actions or levels of action. In some respects, the group's literal interpretation is a more appropriate response to the signage because of their straightforward rationalisation of the information. Other issues identified included Claire's comments about the presence of surfing information centres and that if she or her fellow beach visitors were in danger she would contact lifeguards wearing 'green uniforms'. Those in green uniforms were actually Council workers collecting litter; this mistaken identification therefore indicates the importance of clear information and an identifiable uniform (i.e. red shorts and yellow shirt) for lifeguards. Pauline provided perhaps the most in-depth discussion of danger, noting that, in her opinion, sunburn is the biggest threat to beach users; this supports GP research (Bartram \& Rees, 2000). This is a relevant point because it demonstrates that health campaigns linked to dermatological health have had a positive impact. Overcoming the conceptual difficulties of understanding the link between UV rays and health is not necessary for a compliant policy, only an acceptance of the authority of respected organisations. Hence, safety at beaches needs considered communication through publically accepted authorities, and campaigns need to convince the public and other groups of their authenticity. 
Finally, the presence of strangers at beaches was a concern and this perceived threat formed one fundamental reason why participants stipulated their reluctance to visit beaches unaided. Hence, reflexive interpretation of participants' viewpoints means that it is plausible to hypothesise that this section of society is highly dependent on gatekeepers to instigate a sense of safety when visiting beaches. This leads to the realization that recent policies designed to encourage independence are an appropriate policy direction for LD groups.

\section{Comparison of the GP and LD cohorts}

To contextualise the research further, data from the general public were collected to facilitate $\mathrm{CM}$ decision-making. Figure 3 and Table 2 show that there is general agreement between the groups of the importance of scenery, visitor facilities, physical access and litter/pollution, which complies with the findings of previous studies, e.g. Williams and Micallef (2009). In addition, results confirmed that time of visit, socialising and observation of activities are not particularly important to LD or the general public, which conforms to previous research findings from over 3,000 global beach interviews (Williams, 2011). This supports the argument for the need for CZM to continue to focus efforts on this pattern of relative priorities. However, there were some issues where prioritisation was polarised between the groups.

The largest difference between groups was in relation to recreational activities, buildings and footprints, where, in contrast to the GP cohort, the LD group gave these a high priority (Figure 3). Interviews suggested that, for the LD participants, the importance of recreational activities is due to the excitement associated with beach visits (i.e. a recreational activity in its own right), whereas the GP associate an activity with their arrival on a beach. Furthermore, the gatekeeper organised activities and he acted as the conduit to these activities, leading to the perception of difficulty with independent recreation. In some 
Figure 3 The ranked difference of $L D$ and GP results

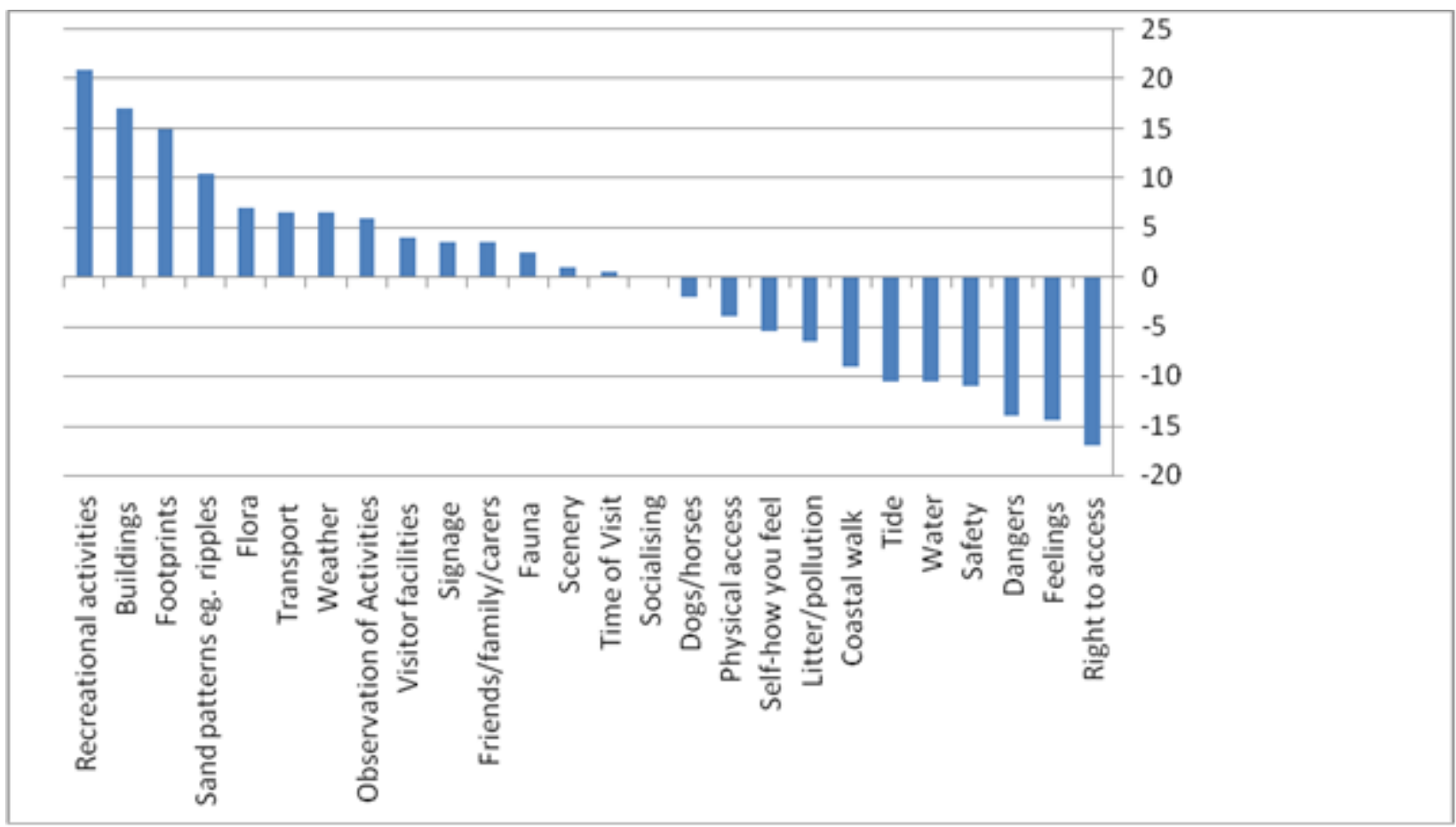


respects, independent recreation by people with LD is implicitly discouraged by traditional institutionalism. Coastal managers need to consider organised activities for such groups and develop communication channels with gatekeepers to establish recreational opportunities with the aim of developing grades of independence. Attitudes to buildings showed a similar set of results: the GP cohort highlighted the aesthetic and the LD group the functional perspective. Architecture on surveyed beaches was often mixed, prefabricated and displayed the stresses of weathering. Hence, coastal managers need to engage with other planning authorities to consider strategically the form and function of coastal buildings, especially in areas with various protected designations. Finally, footprints are temporary beach elements removed by tides or beach-cleaning machinery and consequently are not important to the GP. For LD personnel, however, footprints indicate the presence of people and they feel safer with this thought. From a CM viewpoint, there is an evident low priority for this issue, but a management plan might make note of 'footprint trails'.

In contrast to the group with LD, the GP cohort gave right of access, feelings and dangers a high priority (Figure 3). Right of access appears to be extremely important to the GP cohort, linked to its association with national heritage and public rights. In contrast, the LD group did not consider access as an issue; however, access is strongly significant in CM negotiations with landowners. The strong feelings of the GP cohort are probably associated with the 'sea, sand, sun syndrome' and the 'feel-good factor', as well as the significance of memories. For the LD group it appears that this was a difficult concept to appreciate and, although noted, their appreciation of its conceptual meaning was restricted. Although this is a difficult area for coastal managers to accommodate, positive experiences result in return visits, which has economic relevance. Finally, dangers and safety are interrelated and ranked highly for the GP cohort but not for the LD group: that is, they were not aware of standard dangers that would 
be apparent to the GP. The LD group delegate risk assessment to their gatekeepers, which may be a designed or an inherent approach. This is particularly important for the current ethos that independence should be encouraged and facilitated. Beach managers need to account for this by carefully designing danger awareness strategies, signage and other forms of communication for LD groups. This is a crucial consideration and, when associated with other groups of potentially vulnerable beaches users, such as children and the aged, signage design becomes significant.

\section{Inclusive Coastal Access Model (ICAM)}

From this discussion a new model was developed (Figure 4) based on the 'access chain' system developed in the By all reasonable means document, which used extensive research to support access to the outdoors for disabled people (Countryside Agency, 2005: 1). While the Countryside Agency system provides support regarding pre-visit information, transport and on-site interpretation, it is not specifically designed for coastal locations. This inclusive coastal access model (ICAM) is based on inclusive participatory research and is able to demonstrate the specific alterations and additional information that are required. The model is not only applicable to coastal zone users who have LD but also to other beach users. The findings support Tregaskis (2004), who identifies the requirement for inclusive coastal landscapes to incorporate the needs of the learning disabled person, in addition to those of gatekeepers and the general public.

The cylinder entitled 'Pre-visit information' (Figure 4) outlines the necessary improvements in information services required from coastal zone managers. High priority must be set on the provision of understandable access information to allow people with learning disabilities to demonstrate self-advocacy (Department of Health, 2005) so that they can make informed 
Figure 4 Integrated Coastal Access Model (ICAM)

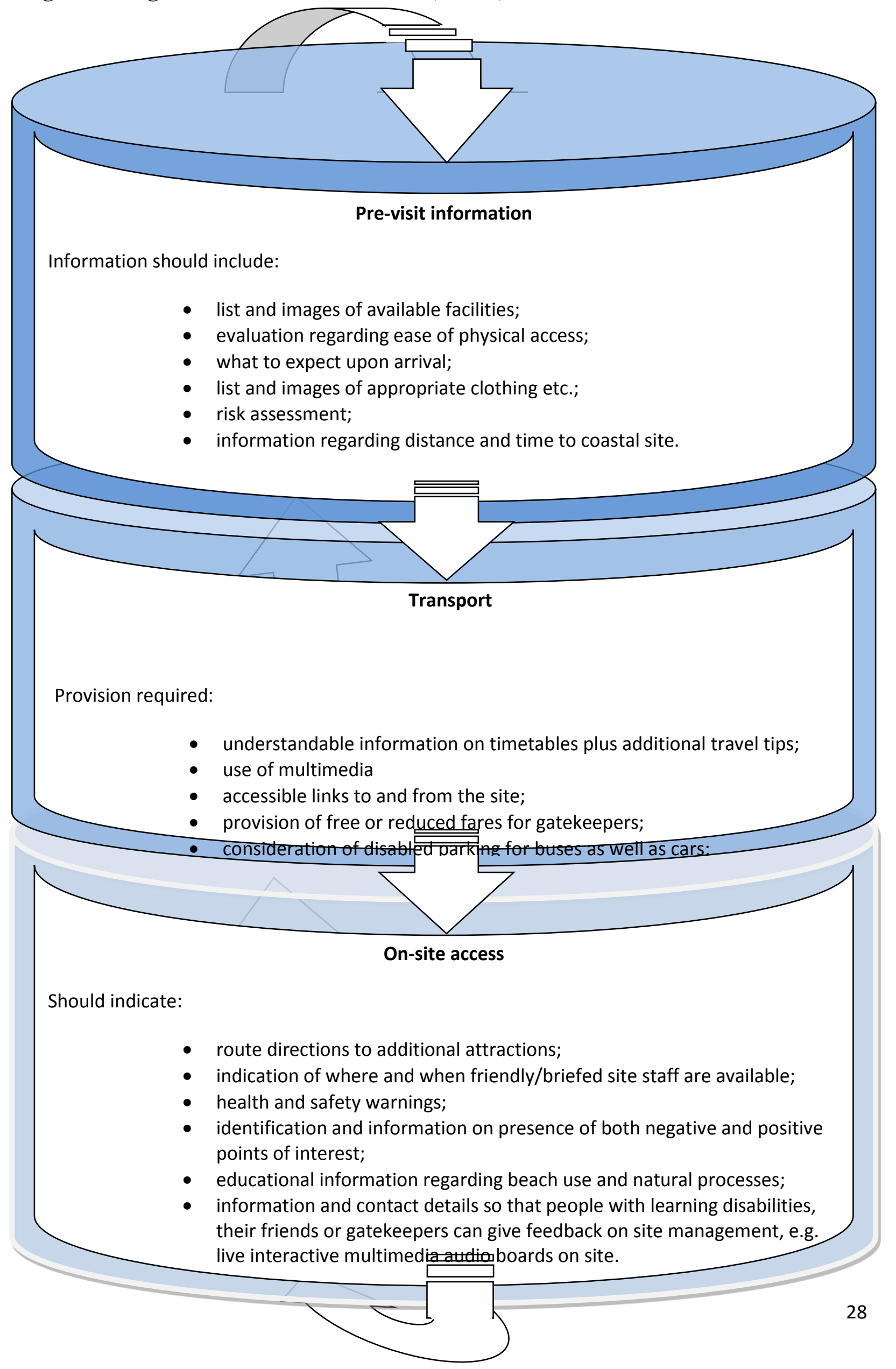


decisions (Mencap, 2002) on which beach they wish to visit and when to do so (e.g. high or low tide). The findings suggest that the communication of this information needs to be carefully considered to ensure understanding and assurance among the LD cohort. Images should be an important part of this process and need to be contemporary and locationspecific: e.g. the use of beach webcams to show contemporary features and changing tides. Furthermore, the gatekeepers need to articulate the fundamentals of the risk assessment to the group and to coastal managers so that relative responsibilities are identified and pre-visit actions undertaken, such as a list of the group's health needs, required responses, contacts and the location of labelled medicines.

The transport section should provide a list of recommendations pertaining to the costeffective promotion and use of public transport links for people with LD. The public transport information needs articulation in appropriate forms, which should include multimedia, so that misinterpretation is minimised. Furthermore, the requirements of car parking facilities and information for the journey home need to be considered, with marked parking located in proximity to facilities and beach access points. Specific beaches could be allocated as LD friendly so that facilities are provided and beach workers are aware of their responsibilities to LD groups. However, LD-friendly beaches need to become the norm and not based on tokenism; this should be supported by the 'real' implementation and monitoring of disability legislation. If the social model is to be further developed, then it is imperative that LD beach users are encouraged to build confidence in planning a trip and/or taking themselves (unaided) to the coast, and this requires planning transport provision.

The on-site access section gives an overview of recommended site improvements for programme access to coastal sites. The concepts presented are transferable to other coastal 
sites but the exact form should be site-specific and based on a formulation process that listens to LD groups and involves gatekeepers and coastal managers. The provision of concise, interesting and understandable signage - and (where appropriate) leaflets, multimedia apps, websites and fact sheets - is fundamental to the inclusion of people with LD within the coastal zone. It is also important that users and managers regularly review the on-site access so that the provision adapts to changing needs and personnel. This is particularly important because the research highlighted the fact that a lot of disabled policy provision is based on one-off capital investments that are visually evident but not necessarily part of a coherent strategy. This lends itself to legislatively informed tokenism and a focus on infrastructural provision for physical disabilities in coastal locations; yet LD needs are by definition not all physical and hence adaptations to the coastal sites need to be carefully considered and not just measured by their visual presence.

\section{Conclusions}

By using a reflexive approach to photo-interpretation, researchers can develop a comprehensive insight into the requirements of coastal zone visitors with LD. It became apparent from this research that access issues raised by participants were multifaceted; in order to aid comprehension, it was possible to categorise participants' ideas into visual, interactive, social, sensory and subjective landscape features. Findings showed that people with LD share some similar interests with the GP regarding coastal zones; however, their needs and requirements are also intrinsically different and more complex. Hence, it is vital that this part of society and their gatekeepers (which could include coastal zone managers) have pre-visit and in-situ information that aids their decision-making and facilitates accessibility. For example, the requirement of signage should reflect guidelines from LD organisations, e.g. Mencap (2002) and the Disability Rights Commission (2004). In addition, 
the form and consideration of coastal physical access features needs incorporation into $\mathrm{CM}$ policies to include depth perception and spatial awareness concerns. Other issues include education in health and safety as well as natural beach processes, and the necessity for informed and, where possible, self-advocacy among learning disabled visitors, who are usually dependent on gatekeepers to provide transport and protection. There is also a significant demand for inclusive access for care workers, family members and friends in addition to providing for the needs of visitors with LD. The ICAM model provides a systematic approach for those wishing to improve coastal access for all coastal visitors. As expressed by Tregaskis (2004), improvements pertaining to the inclusion of the disabled generally benefit the wider population as well. Finally, it is evident that the LD 'silent majority' of the designated disabled population need further consideration within ICM. However, this consideration will require further baseline studies and development of an ICAM that embeds findings into ICM.

\section{References}

Balomenou, N. and Garrod, B. (2014) Using volunteer-employed photography to inform tourism planning decisions: a study of St David's Peninsula, Wales, Tourism Management 44, 126-139.

Bartram, J. and Rees, G. (Eds.) (2000) Monitoring bathing waters: a practical guide to the design and implementation of assessments and monitoring programmes, Taylor \& Francis, Oxford.

Booth, T. and Booth, W. (2003) In the frame: photovoice and mothers with learning disabilities, Journal of Disability and Society, 18(4), 431-442. 
Botterill, D. and Klemm, M. (2006) Tourism and Social Inclusion, Tourism, Culture and Communication, 7(1), 1-4.

Clarke, B., Stocker, L., Coffey, B., Leith, P., Harvey, N., Baldwin, C., Baxter, T., Bruekers, G., Galano, C.D., Good, M., Haward, M., Hofmeester, C., De Freitas, D.M., Mumford, T., Nursey-Bray, M., Kriwoken, L., Shaw, J., Smith, T., Thomsen, D., Wood, D. and Cannard, T. (2013) Enhancing the knowledge-governance interface: coasts, climate and collaboration, Ocean \& Coastal Management, 86, 88-99.

Clegg, J. (2004) Practice in focus: a hermeneutic approach to research ethics, British Journal of Learning Disabilities, 32, 186-190.

Countryside Agency (2005) By all reasonable means: inclusive access to the outdoors for disabled people, Countryside Agency, Cheltenham.

CSR Europe (2007) Disability: facts and figures.

http://www.csreurope.org/csrinfo/csrdisability/DisabilityFactsandfigures/ (accessed October $12,2010)$

Dakin, S. (2003) There's more to landscape than meets the eye: towards inclusive landscape assessments in resource and environmental management, The Canadian Geographer, 47(2), 185-200.

DDA (1995) Disability Discrimination Act and amendments.

http://www.legislation.gov.uk/ukpga/1995/50/introduction\#openingWholeMod (accessed October 14, 2010)

Department of Health (2001) Valuing people: a new strategy for learning disability for the 21st century, Department of Health, London. 
Department of Health (2005) Valuing people: Making things better, Department of Health, London.

Disabled World (2011) Latest U.S. disability statistics and facts http://www.disabledworld.com/disability/statistics/census-figures.php (accessed April 28, 2015)

Disability Rights Commission (2004) Good signs: improving signs for people with a learning disability, Disability Rights Commission, Stratford upon Avon.

Dye, L., Hendy, S., Hare, J.D. and Burton, M. (2004) Capacity to consent to participate in research: a recontextualization. British Journal of Learning Disabilities 32, 144-150.

Equality Act (2010) Equality Act.

http://www.legislation.gov.uk/ukpga/2010/15/contents\#openingWholeMod (accessed May $17,2012)$

Ergin, A., Micallef, A. and Williams, A.T. (2006) Coastal scenery: appreciation and evaluation. Journal of Coastal Research, 22(2), 958-964.

Ergin, A., Micallef, A., and Williams A.T. (2008) Coastal scenic evaluation of Gozo/Comino, Malta, as a tourism product. In Proc. of the International Pluridisciplinary Conference: Le littoral: subir, dire, agir, IFRES/MESHS, 2008 (electronic pub.). http://www.meshs.fr/documents/pdf/publications/actes/colloque_littoral/Ergin.pdf (accessed April 24, 2015)

European Commission (2007) Including people with disabilities: Europe's equal opportunities strategy. European Commission, Brussels. 
European Commission (2009) Mid-term evaluation of the European Action Plan 2003-2010 on Equal Opportunities for people with disabilities. Centre for Strategy \& Evaluation Services, Sevenoaks.

European Commission (2010) European Disability Strategy 2010-2020: a renewed commitment to a barrier-free Europe. European Commission, Brussels.

FPLD (Foundation for People with Learning Disabilities) (2003) Statistics on learning disabilities. http://www.learningdisabilities.org.uk/page.cfm?pagecode (accessed October 12, 2010)

FPLD (Foundation for People with Learning Disabilities) (2014) A complete guide to learning disabilities, topical issues and sources of support.

http://www.learningdisabilities.org.uk/help-information/learning-disability-a-z/ (accessed April 24, 2015)

Germain, R. (2004) An exploratory study using cameras and 'talking mats' to access the views of young people with learning disabilities on their out-of-school activities, British Journal of Learning Disabilities, 32, 170-174.

Goodall, B. (2006) Disabled access and heritage attractions, Tourism, Culture and Communication, 7, 57-78.

Haines-Saah, R.J., Oliffe, J.L., White, C.F. and Bottorff, J.L. (2013) 'It is just not part of the culture here': young adults' photo-narratives about smoking, quitting, and healthy lifestyles in Vancouver, Canada, Health \& Place, 22, 19-28.

Hanley, B. (2005) Research as empowerment. Joseph Rowntree Foundation, York. 
Hurworth, R., Clark, E., Martin, J. and Thomsen, S. (2005) The use of photo-interviewing: three examples from health evaluation and research, Evaluation Journal of Australasia, 4(1 \& 2), 52-62.

Knight, A., Clark, A., Petrie, P. and Statham, J. (2006) The views of children and young people with learning disabilities about the support they receive from social services: a review of current literature, Thomas Coram Research Unit, London.

Lawler, J. and Patel, M. (2012) Exploring children's vulnerability to climate change and their role in advancing climate change adaptation in East Asia and the Pacific, Environmental Development, 3, 123-136.

Leatherman, S.P. (2001), Social and economic costs of sea level rise. In Douglas, B.C., Kearney, M.S. and Leatherman, S.P. (Eds.) Sea level rise: history and consequences. Academic Press, San Diego, 181-223.

Lewis, A. and Porter, J. (2004) Interviewing children and young people with learning disabilities: guidelines for researchers and multi-professional practice, British Journal of Learning Disabilities 32, 191-197.

McKenna, J. and Cooper, A. (2006) Sacred cows in coastal management: the need for a 'cheap and transitory' model, Area 38(4), 421-431.

Mencap (2002) Mencap guidelines: am I making myself clear. Mencap, London.

Nelson, C., Williams, A.T. and D., Botterill. 2003. Conceptual modeling of beach management: South Wales case studies. In E. Ozhan (ed.) Proc. of the 6th Int. Conf. on the Med. Environment, 2003 (ed.) Middle East Technical University, Ankara, Turkey, 13211332 
NetBuddy (2012) Forum survey published 7 February, 2012.

http://netbuddytoptips.blogspot.co.uk/2012/02/language-can-be-minefield-particularly.html (accessed March 2, 2014)

Newdisability, n.d. Wheelchair statistics: How many wheelchair users are there? http://www.newdisability.com/wheelchairstatistics.htm (accessed April 28, 2015)

PECS (2014) Picture Exchange Communication System (PECS) and the pyramid approach to education. http://www.pecs-unitedkingdom.com/ (accessed January 7, 2014)

Phillips, M.R. and House, C. (2008) An evaluation of priorities for beach tourism: case studies from South Wales, UK. Tourism Management, 30, 176-183.

Rangel-Buitrago, N., Correa, I., Anfuso, G., Ergin, A. and Williams, A.T. (2013) Assessing and managing scenery in the Caribbean coast of Columbia, Journal of Tourism Management, $35,41-58$.

Scope (2015) Scope's blog http://blog.scope.org.uk/ (accessed April 28th, 2015)

Small, C. and Nicholls, R.J. (2003), A global analysis of human settlement in coastal zones, Journal of Coastal Research, 19(3), 584-600.

Spink, A.G. (2005) Disabled 'suffer worst exclusion'. http://news.bbc.co.uk/1/hi/uk/4070792.stm(accessed October 18, 2010)

Stewart, P.W., Liebert, D. and Larkin, W.K. (2004) Community identities as visions for landscape change, Landscape and Urban Planning, 69, 315-334. 
Tregaskis, C. (2004) Applying the social model in practice: some lessons from countryside recreation, Disability and Society, 19(6), 601-611.

UN (2006) Convention on the Rights of Persons with Disabilities.

http://www.un.org/disabilities/convention/conventionfull.shtml (accessed May 22, 2011)

Wang, C. (2005) Photovoice.(accessed October 13, 2010)

Wang, C. and Burris, M.A. (1997) Photovoice: concept, methodology, and use for participatory needs assessment, Health Education and Behavior, 24(3), 369-387.

WHO (2011) World report on disability, World Health Organisation, Geneva.

Williams, A.T., 2011. Definitions and typologies of coastal tourism destinations. In A. Jones and M. Phillips (Eds.) Disappearing destinations: climate change and future challenges for coastal tourism, CABI, UK: 47-66.

Williams, A.T. and Lavalle, C.D. (1990) Coastal landscape evaluation and photography, Journal of Coastal Research, 6(4), 1011-1020.

Williams, A.T. and Micallef, A. (2009) Beach management: Principles and practice. Earthscan, London.

Williams, A.T. and Tudor D.T. (2009) Preferences and priorities of beach users on the south shore of the Bristol Channel, UK, Shore and Beach, 77(1), 1-6.

Williams, A.T. and Williams M.J. (1988) The perception of and adjustment to rockfall hazards along the Glamorgan heritage coast, Wales, UK, Ocean \& Shoreline Management, 11, 319-339. 
Williams, A.T., and Williams M.J. (1991) The perceived effectiveness of coastal warning signs. In G. Cambers (ed.), Coastlines of the Caribbean. Amer. Soc. Civil Eng., New York: $70-84$.

Woodgate, R.L., Edwards, M. and Ripat, J. (2012) How families of children with complex care needs participate in everyday life, Social Science \& Medicine, 75(10), 1912-1920.

Yamashita, S. (2002) Perception and evaluation of water in landscape: use of photoprojective method to compare child and adult residents' perceptions of a Japanese river environment, Landscape and Urban Planning, 62, 3-17. 